\title{
Multifunctional Ground Control Points with a Wireless Network for Communication with a UAV
}

\author{
Xiongzhe Han ${ }^{1, *}$, J. Alex Thomasson ${ }^{1}$, Yang Xiang ${ }^{2}$, Hussein Gharakhani ${ }^{1}$, Pappu K. Yadav ${ }^{1}$ \\ and William L. Rooney ${ }^{3}$ \\ 1 Department of Biological and Agricultural Engineering, Texas A\&M University, \\ College Station, TX 77843, USA \\ 2 College of Engineering, Hunan Agricultural University, Changsha, Hunan 410128, China \\ 3 Department of Soil and Crop Sciences, Texas A\&M University, College Station, TX 77843, USA \\ * Correspondence: hanxiongzhe@tamu.edu; Tel.: +1-979-777-3628
}

Received: 28 May 2019; Accepted: 25 June 2019; Published: 27 June 2019

check for

\begin{abstract}
Ground control points (GCPs) are commonly used for georeferencing in remote sensing. Precise position measurement of the GCPs typically requires careful ground surveying, which is time-consuming and labor-intensive and thus excessively costly if it needs to be repeated multiple times in a season. A system of multifunctional GCPs and a wireless network for communication with an unmanned aerial vehicle (UAV) was developed to improve the speed of GCP setup and provide GCP data collection in real-time during the flight. While testing the system, a single-board computer on a fixed-wing UAV used in the study successfully recorded position data from all the GCPs during the flight. The multifunctional GCPs were also tested for use as references for calibration of reflectance and height for field objects like crops. The test of radiometric calibration resulted in an average reflectance error of $2.0 \%$ and a strong relationship $\left(R^{2}=0.99\right)$ between UAV-based estimates and ground reflectance. Furthermore, the average height difference between UAV-based height estimates and ground measurements was within $10 \mathrm{~cm}$.
\end{abstract}

Keywords: ground control points; unmanned aerial vehicle; wireless network; radiometric calibration; height calibration

\section{Introduction}

Unmanned aerial vehicles (UAVs) are being used in agricultural research to collect images for various tasks including biomass monitoring, crop yield estimation, disease detection, and water status estimation [1-3]. In transitioning, for these type of data to on-farm use, high accuracy is critical to reliable decision-making. Accurate positions in three-dimensional (3D) space require georeferencing of the UAV images $[4,5]$. Other requirements for high accuracy can include calibrating radiometric reflectance from multispectral-camera images and object height from digital surface models (DSMs).

Ground control points (GCPs) with precisely measured positions are needed to improve the geometric accuracy and quality of digital terrain models (DTMs), DSMs, and orthomosaic maps [6-8] unless a direct georeferencing technique is used [9]. Such GCPs are commonly used for georeferencing and are designed to be clearly visible and large enough in images so that a center point can be accurately and precisely marked from the flight altitude. It is crucial that the UAV has an unobstructed view of the GCPs from the sky and that shadows from close-by objects are avoided. A precise location measurement based on real-time kinematic (RTK) or post processing kinematic (PPK) global positioning system (GPS) is required for optimal use of GCPs. In addition, GCPs should be spread across the ground area of the flight zone and should cover both high and low elevations [10]. 
Precise position measurement commonly requires careful ground surveying, which is time-consuming and labor-intensive and thus excessively costly if it needs to be repeated multiple times in a growing season. The commercially available AeroPoint GCP (Propeller Aero, Sydney, NSW, Australia) is reportedly simple to use, portable, reusable, and commonly used (e.g., in surveys for mining) to record its position during UAV flights [11]. Multiple Aeropoints can be used collaboratively to increase the accuracy of each unit in the field. Researchers in agricultural and forestry remote sensing have used AeroPoints as geographic references [12,13], but these GCPs need to be active for at least $45 \mathrm{~min}$ to record enough position data to be survey-grade accurate, and they would typically need to be distributed across the field immediately prior to each flight mission. Thus, their use may not be practical in agricultural-production situations. Moreover, the GCPs utilized in agricultural remote sensing research have typically been used as single-purpose devices, such as for only position measurement, but they can potentially also serve as references for other measurements.

While agricultural remote sensing requires accurate position data $[14,15]$, it may also require accurate radiometric and plant-height data. Radiometric calibration is essential to generate consistent remotely sensed reflectance imagery under a wide variety of environmental conditions $[16,17]$. Height calibration can also be used to improve the accuracy of plant height estimation from a DSM [18].

For high geometric accuracy, the 3D coordinates of GCPs are typically surveyed with a GPS receiver working in PPK or RTK mode with a base station on a geodesic pillar located closer than one kilometer from the studied surfaces $[19,20]$. At least five GCPs are recommended to maximize accuracy, but further increasing the number of GCPs leads to even higher accuracy in point clouds, orthomosaics, and DSMs [21,22]. If multiple GCPs have to be positioned in the field, particularly if this process must occur multiple times during a growing season, manually surveying their positions is burdensome and most likely impractical on farms. However, if GCPs could not only measure their own position as Aeropoints do, but do so quickly and also communicate the data to an over-flying UAV, GCP position could potentially be embedded in the image metadata, and the efficiency of data processing could be significantly improved.

In recent research [23], software has been developed to use GCPs in UAV-based image mosaics to automatically correct them for radiometric fidelity. The software recognizes reflectance targets on the GCPs, extracts digital numbers from them, and calibrates the entire mosaic. This software can replace the conventional semi-manual methods that are typically required to process the raw image data after the flight. However, additional automated systems are needed to make UAV-based remote sensing practical on-farm.

Communications in agricultural fields are a relatively new phenomenon, but wireless sensor networks are becoming commonplace for applications like weather monitoring and irrigation management [24-26]. Among other variables, the sensors may collect data on humidity, temperature, and soil moisture, all significant environmental parameters for plant growth [27-30]. The design of an agricultural sensor network should ensure the availability and authenticity of the data. Certain network architectures, mechanisms, and algorithms have been developed to ensure high-quality communication. Individual networked sensors typically serve as nodes in the network, and this design increases transmission efficiency for precision-agriculture applications [31-33] and can ensure reliability in communication. While wireless sensor networks are becoming more common in production agriculture, they have not been researched for real-time communication between UAVs and ground-based references to enable acquisition of reference information for high-quality imagery for precision agriculture.

As previously mentioned, there are limitations to use GCPs in agricultural remote sensing with UAVs. Current research gaps include a lack of utilizing GCPs for other referencing needs like radiometric and plant-height calibrations as well as a lack of study on wireless networks that could link UAVs and GCPs in real time for automated reference data collection.

The overall goal of this research involves developing an autonomous GCP system including a wireless network for position-data collection and communication with an UAV. Such a system could 
improve the speed of GCP setup and provide data collection advantages that have broad application in agriculture and environmental monitoring. Specific objectives of this study were (1) to design, build, and test portable GCPs for multiple referencing purposes (georeferencing, radiometric calibration, and height calibration); (2) to develop and test a wireless network for automatic GCP position data collection and automatic communication with a UAV; and (3) to evaluate the system in terms of quality of calibration for reflectance and plant-height maps.

\section{Materials and Methods}

\subsection{System Architecture and Principles}

The entire GCP system (Figure 1) includes a GPS base-station with a main control terminal serving as a central coordinator, a laptop running a custom user interface to serve as a monitoring terminal for the experiment, several GCPs carrying subordinate GPS receivers, a fixed-wing UAV, and a wireless network with multiple hardware and software components. The main control terminal (Figure 2a) included a low-cost GPS module (C94-M8P RTK-GPS; Ublox, Thalwil, Switzerland) serving in base mode, an STM32 microcontroller (STM32F103C8T6; STMicroelectronics, Geneva, Switzerland), and an XBee radio transceiver (XBP9B-DMST-002; Digi International, Minnetonka, MN, USA). Differential-correction signals collected by the base station were transmitted through a universal asynchronous receiver/transmitter (UART) serial communication interface to the STM32 microcontroller, which then broadcasted them to the GCPs through the XBee radio transceiver.

Each GCP included two of the low-cost GPS modules acting in rover mode, an STM32 micro controller, a solar collector and controller (L02P25X-CB-1; ECO-WORTHY, Taiwan, China), a $12 \mathrm{~V}$ battery, and an XBee radio transceiver (Figure 2b). The GPS modules were used to measure horizontal and vertical positions of the GPS antennas at $10 \mathrm{~Hz}$ with a baud rate of 19,200 bps, and having two GPS modules on each GCP enabled calculation of the angle of attitude of each GCP in the field. The angle of attitude is important if one is attempting to use software to automatically identify a GCP in the image data. The STM32 microcontroller was a relatively inexpensive processing chip for communicating with the main control terminal through the Xbee radio transceiver. The differential-correction signals produced by the main control terminal were used to correct the output of the two GPS modules on each GCP to improve positioning accuracy in real time. The solar collector and controller were used to charge the $12 \mathrm{~V}$ battery, which powered all the hardware on each GCP.

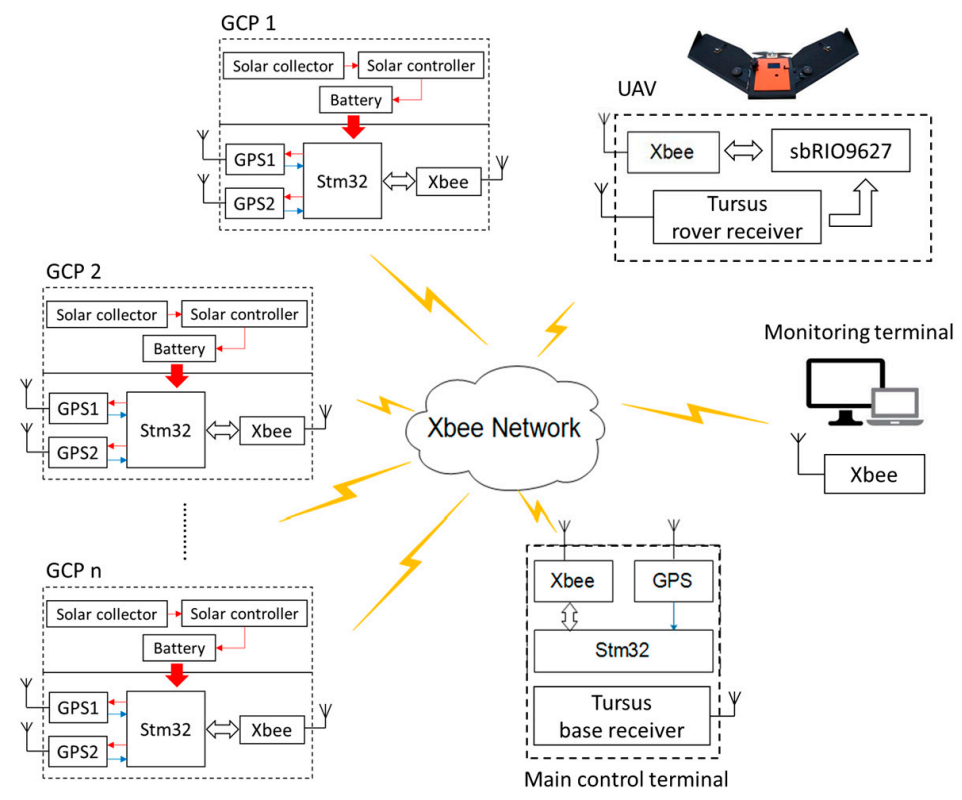

Figure 1. Overall schematic diagram of the wireless system network. 


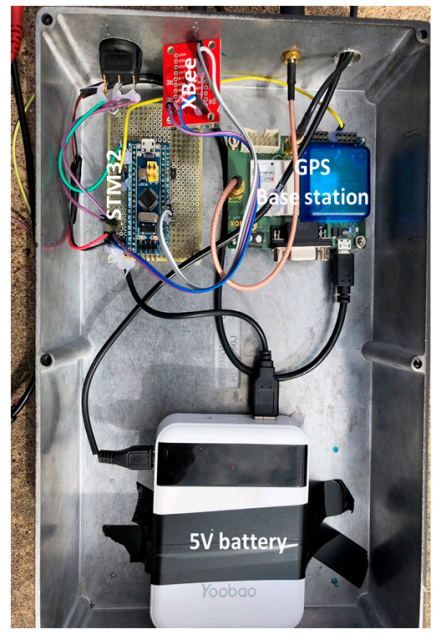

(a)

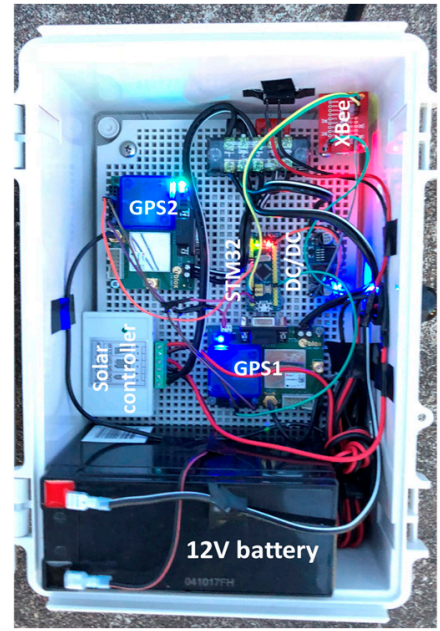

(b)

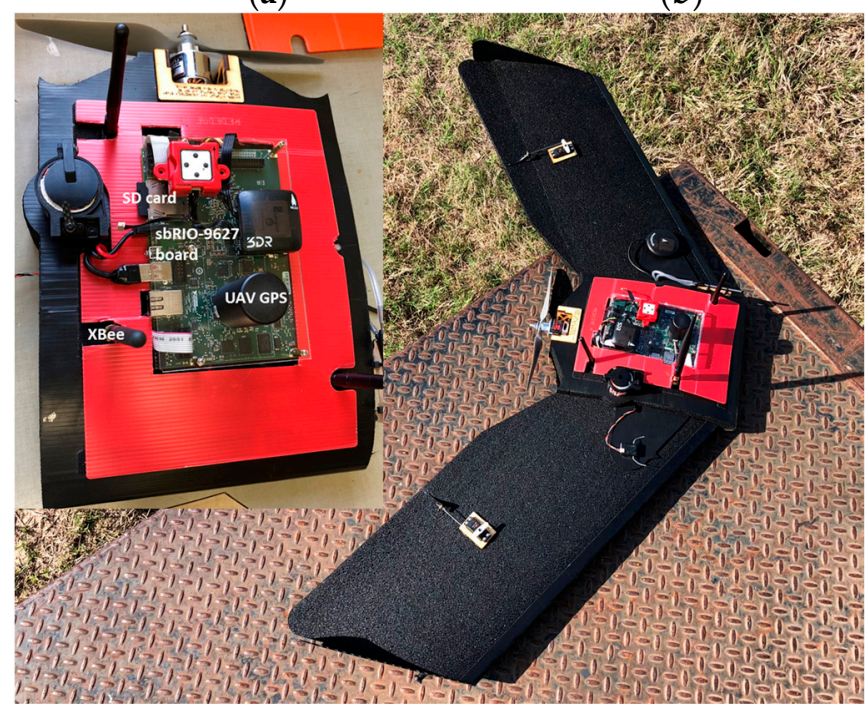

(c)

Figure 2. View of (a) the main control terminal, (b) the integrated ground control point (GCP) controller and (c) the embedded control board on the fixed-wing unmanned aerial vehicle (UAV).

The corrected GPS data on the GCPs were sent to the main control terminal through the Xbee radio transceiver and comprised latitude, longitude, and elevation of each GPS antenna. The final data package, including all GCP information assembled as a text file by the main control terminal, was transferred through the Xbee module to an SD card in an embedded single-board computer (sbRIO-9627; National Instrument, Austin, TX, USA) on an airborne UAV and also to a laptop used for monitoring. The fixed-wing UAV used in this research (Tuffwing Mapper; Tuffwing LLC, Boerne, TX, USA; Figure 2c) was equipped with a more-expensive GPS receiver (BX305; Tersus Gnss Inc., Shanghai; China), which received a correction signal from a similar base receiver on the main control terminal. Thus, for purposes of this experiment, the main control terminal housed two different types of GPS receivers acting as base stations for the different types of rover GPS receivers on the GCPs and the UAV. It should be noted that the simplest conceivable version of the GCP system would have neither a monitoring terminal nor a base station, assuming a local differential correction signal was available. In such a case the remaining functions of the main control terminal could be moved to the single-board computer on the UAV. 


\subsection{GCP Structure}

Portable and foldable (Figure 3a) GCPs were designed with aluminum frames to minimize weight while maintaining strength and functionality. The structure of the GCPs was to be an improvement over an earlier version constructed with wooden frames that were affixed to the ground to act as a semi-permanent calibration system in a previous study [18]. Each new GCP was to have two layers with three 24-inch square reflectance references (dark, medium, and light gray) installed on each layer (Figure $3 \mathrm{~b}$ ). The height from the ground to the bottom and top panels was to be 36 and 72 inches, respectively. The bottom panel was designed to be extended outward to avoid shadows cast from the upper layer onto the lower layer (Figure 3c). The weight of the GCP was $20 \mathrm{~kg}$ without any controller components. Seven of these GCPs were constructed and used in this research.

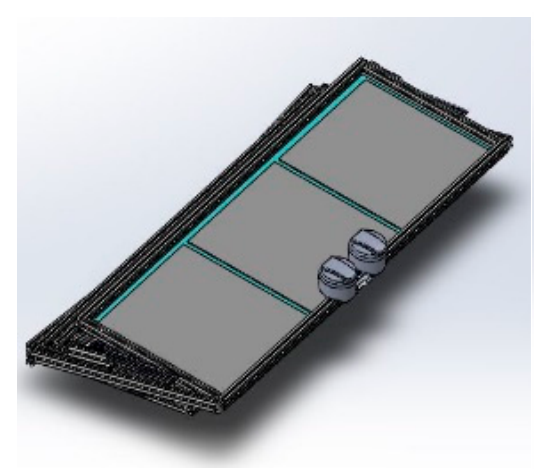

(a)

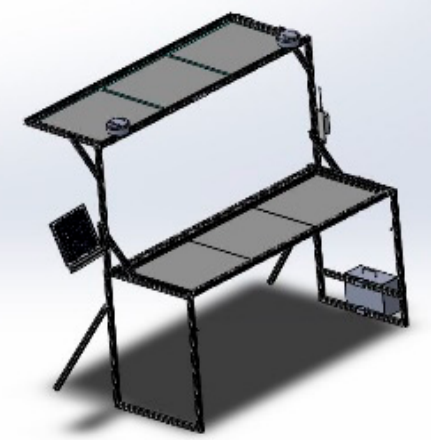

(b)

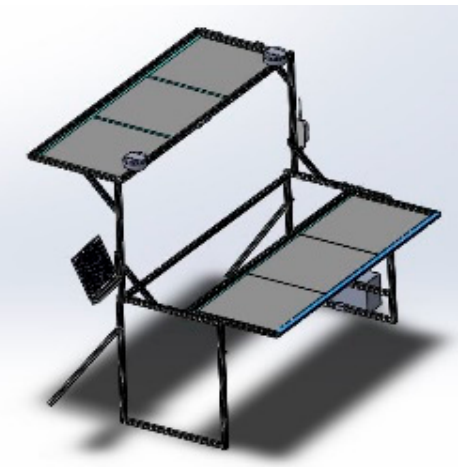

(c)

Figure 3. Structure of the aluminum frame of the multi-functional GCP which is (a) portable, (b) two level layers and (c) extendible for the bottom panel.

\subsection{Data Processing Strategy}

The embedded radio modem on the low-cost GPS modules had a limited number of channels that constrained the ability to connect multiple rover GPS modules with the common base station. Thus, external power of 3.3 VDC was applied to appropriate ports on the GPS modules to turn off the radio modems and enable external UART communication. The differential-correction data provided by the main control terminal were transferred to the STM32 microcontroller at a frequency of $1 \mathrm{~Hz}$. Prior to the transmission, a marker was added at the beginning and end of the GPS sentence associated with the differential correction data for the purpose of unambiguous reception. These markers were removed by the microcontroller on each GCP before the differential-correction data were used to correct the GPS data on the GCPs.

The main control terminal was configured as the central coordinator of the wireless network to avoid communication conflicts between the GCPs and the UAV. Once the receiving status of the GPS modules was fixed at centimeter-level accuracy, usually within 2 min of start-up, each GPS data package was temporarily saved in the internal memory of the associated GCP's STM32 microcontroller. Table 1 shows the format of a query instruction, which was transmitted in a hexadecimal string including two bytes "0x6677" for a start marker and one byte "0x88" for an end marker. The device ID in Table 1 indicates the requested target GCP among the GCPs distributed in the field, and the instruction ID is $10 \mathrm{H}$, which represents the query command for GCP position information from each GCP. When a particular GCP's device ID was specified in the UAV's query instruction, the GPS data package of that GCP was sent to the main control terminal in the format shown in Table 2. The data package was a 20-byte string sentence, including positions (i.e., latitude, longitude, and elevation) for the left and right sides of the GCP, with two bytes "0x6688" for a start marker (Figure 4). The GCP data sentence was formed in the main control terminal and sent to the fixed-wing UAV by encapsulating the data in the aforementioned format. 
Table 1. Format of the GCP query instruction.

\begin{tabular}{ccccc}
\hline Start Marker & Device ID & Instruction ID & End Marker & CRC16 Check \\
\hline 2 bytes & 1 byte & 1 byte & 1 byte & 2 bytes \\
\hline
\end{tabular}

Table 2. Format of the global positioning system (GPS) data package of the requested GCP.

\begin{tabular}{cccccccccc}
\hline $\begin{array}{c}\text { Start } \\
\text { Marker }\end{array}$ & $\begin{array}{c}\text { Device } \\
\text { ID }\end{array}$ & Length & $\begin{array}{c}\text { Long } \\
\text { Left }\end{array}$ & Lat Left & $\begin{array}{c}\text { Long } \\
\text { Right }\end{array}$ & $\begin{array}{c}\text { Lat } \\
\text { Right }\end{array}$ & Alt Left & $\begin{array}{c}\text { Alt } \\
\text { Right }\end{array}$ & CRC 16 \\
\hline 2 bytes & 1 byte & 1 byte & 4 bytes & 4 bytes & 4 bytes & 4 bytes & 2 bytes & 2 bytes & 2 bytes \\
\hline
\end{tabular}

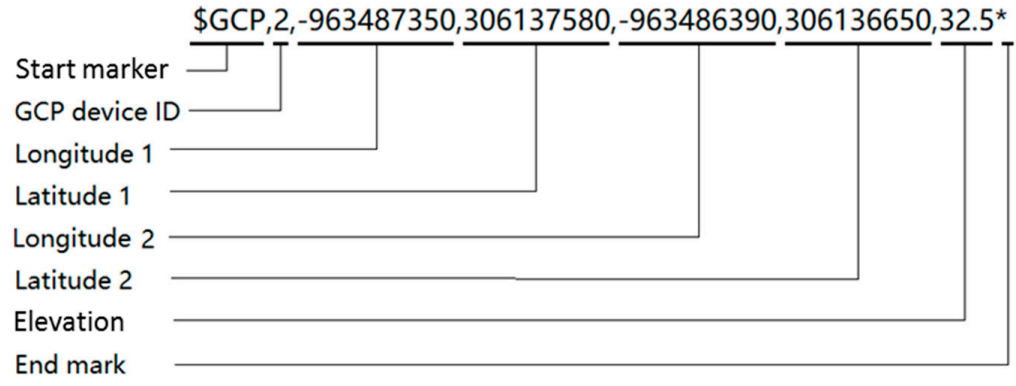

Figure 4. Structure of the GCP data transferred from the main controller to the UAV.

\subsection{Field Testing}

\subsubsection{Accuracy Assessment}

The base station (Figure 5a) was installed precisely on a position near the test field that was part of the Online Positioning User Service maintained by National Geodetic Survey [34], which provides simplified access to high-accuracy National Spatial Reference System coordinates. Seventy GCPs (Figure 5b) were developed for the prior 2017 research season, and eight were used for a prior study [17]. Four of the 70 were used in 2018 as positional references to evaluate the accuracy of the new GCPs. The 2017 GCPs had been held in place with steel anchors since the prior season. The positional correction signal was used from base stations installed at the same National Geodetic Surveyed position in both 2017 and 2018. A Trimble R8 GNSS unit and R7 base station, with an accuracy of $1 \mathrm{~cm}+1 \mathrm{ppm}$ horizontal and $2 \mathrm{~cm}+1 \mathrm{ppm}$ vertical after post-correction, were used to collect a GPS position measurement at the front left and front right corners of the lower layer on all GCPs used in 2017. The antennas of the new GCPs were also placed on the same positional reference locations of the previous GCPs to compare the horizontal and vertical accuracies and allow observation of measurement stability in the new low-cost GCP system.

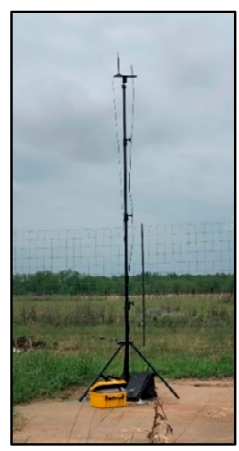

(a)

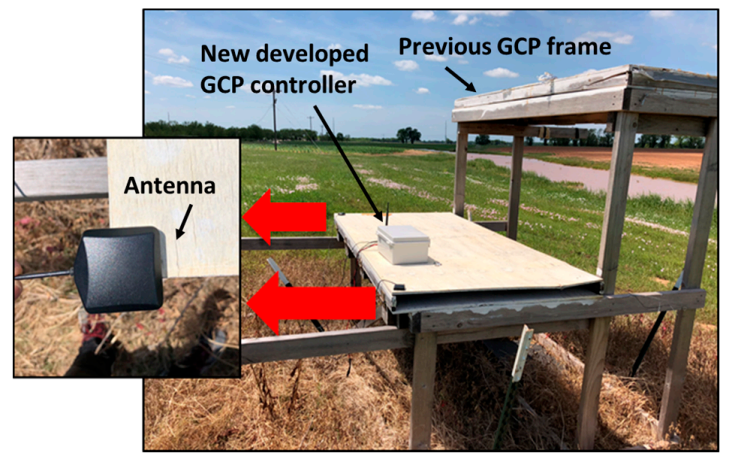

(b)

Figure 5. View of (a) the base station on the surveyed position and (b) the accuracy assessment test in the field. 


\subsubsection{Validation Experiment}

The Tuffwing UAV was flown with a multispectral camera (RedEdge; MicaSense, Seattle, WA, USA) at an altitude of $120 \mathrm{~m}$ above ground level (AGL) and a ground speed of approximately $17 \mathrm{~m} / \mathrm{s}$. Figure 6a shows the planned flight path used during flight missions, which achieved sufficient side overlap for subsequent image mosaicking. The new GCPs were distributed across a field of $0.35 \mathrm{~km}^{2}$ area at Texas A\&M AgriLife Research farm near College Station, TX, USA. Three crop types-cotton, corn, and sorghum (Figure $6 \mathrm{~b}$ ) - were covered in this study. The wireless network was used to determine whether all GCP information could be successfully transmitted and recorded as image metadata onboard the UAV during flight, for purposes of georeferencing, radiometric calibration, and height calibration. A custom user interface program was written in Labview to run on the monitoring terminal, so that the reception status of the GCPs could be verified in real time.

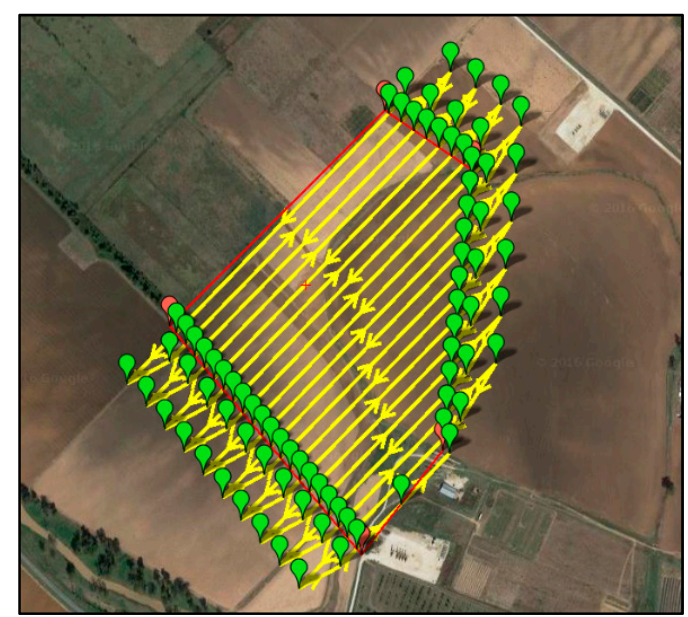

(a)

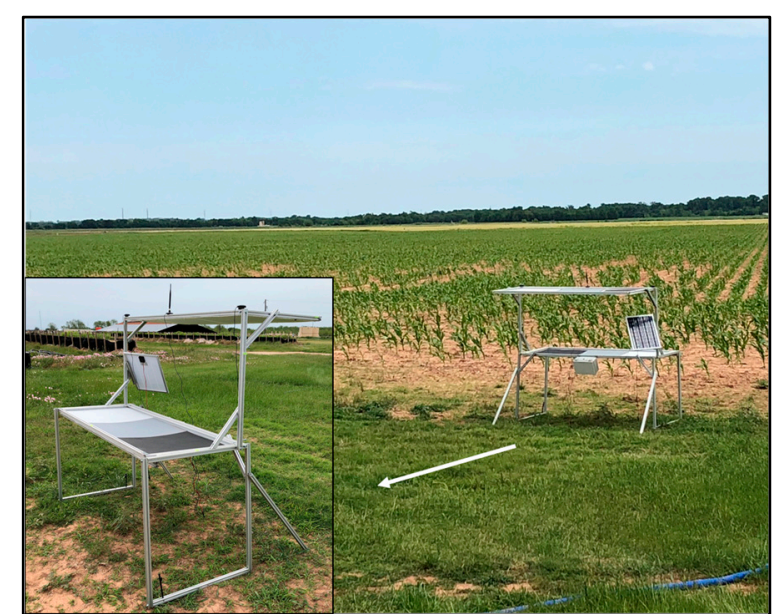

(b)

Figure 6. View of (a) the planned flight path pattern generated for the UAV and (b) the validation test in the field.

The seven GCPs were distributed to broadly cover the test field (Figure 7). To minimize the effects of changing illumination and atmospheric conditions on UAV images, radiometric calibration was conducted by using the reflectance references on the GCPs. Roughly 30 image pixels were extracted from each calibration reference on GCPs 1 through 5 to determine the median reflectance values for each band of the multispectral camera. Ground reflectance (\%) measurements were collected from five uniformly distributed points on each calibration reference with a handheld spectrophotometer (PSR+; Spectral Evolution, Lawrence, KS, USA) within $15 \mathrm{~min}$ after the flight. The median reflectance values of the calibration references were obtained from the five spectral bands. A calibration equation was derived by fitting the digital numbers DNs of the images to the reflectance values of the calibration references for each band, the DNs of each band were converted to normalized reflectance values. To validate the radiometric calibration, the average reflectance error for each band in the calibrated image mosaic was calculated based on measurements of GCPs 6 and 7, which were located at different positions in the field from the five GCPs used for calibration.

Consistent with the method used in a previous study $[18,35,36]$, height calibration of the image mosaic from each flight test was performed with a linear equation based on three points extracted from each GCP location for GCPs 1 through 5: Ground elevation immediately adjacent to the GCP, the GCP's lower layer, and the GCP's upper layer. The DTM had been created by using structure-from-motion on image data collected previously during bare-ground conditions. Similar to the test for radiometric calibration, the average height error in the calibrated DSM was calculated based on each level of GCPs 6 and 7. 


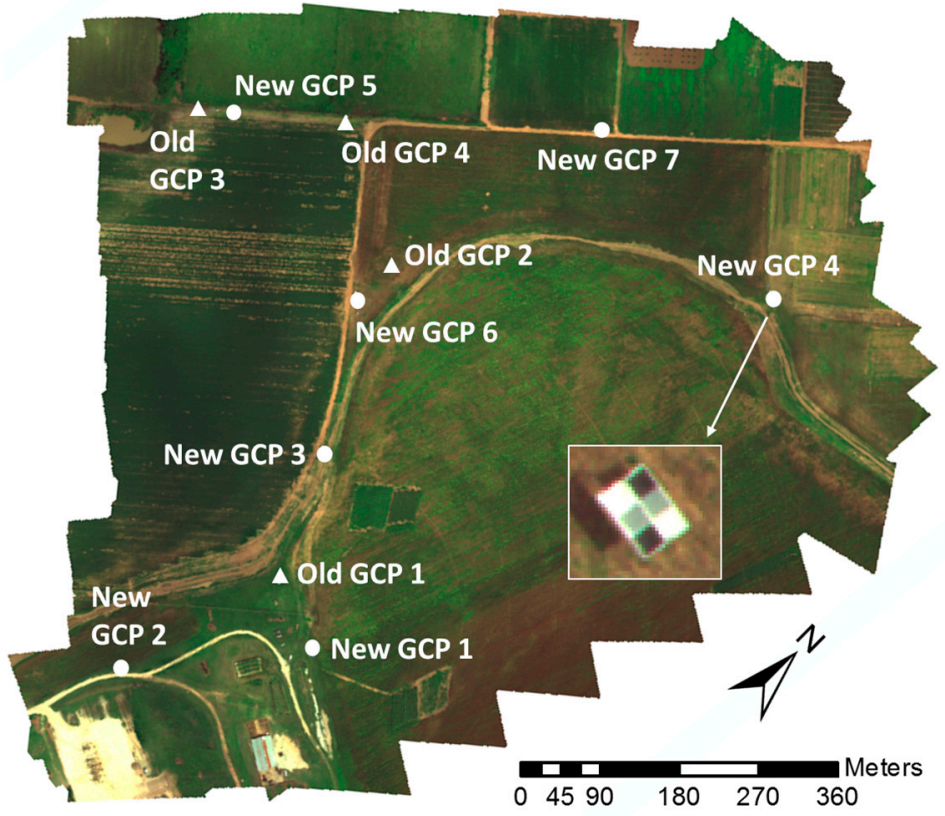

Figure 7. Distribution of all GCPs in the experiment field at Texas A\&M AgriLife Research farm.

\section{Results and Discussion}

\subsection{GCP Physical System and Position Accuracy}

Figure 8 shows a portable, foldable, multifunctional GCP as constructed and placed in the field. The cost of materials and components of each GCP system was $\$ 480$. All hardware components of each GCP were powered successfully by the battery, which was recharged by the solar collector. The time required for GCP setup by two workers was approximately $40 \mathrm{~s}$, and the time spent measuring and recording GCP positions with the wireless network was approximately $2 \mathrm{~min}$, compared to 30 to $60 \mathrm{~min}$ when placed manually, a particularly important consideration when data collection must be repeated multiple times in a season.

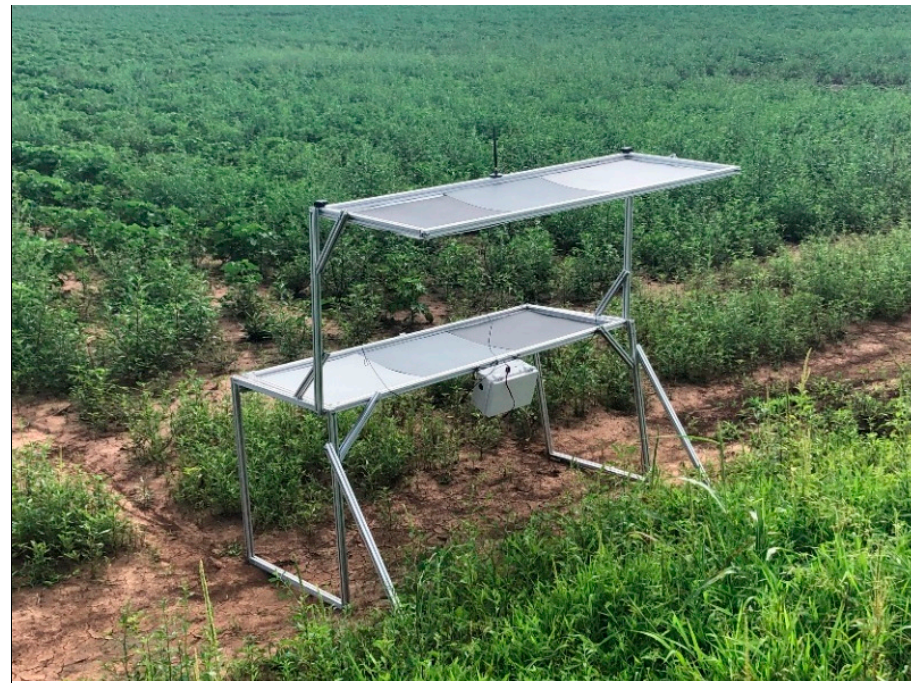

Figure 8. Real constructed multifunctional GCP used for georeferencing, radiometric calibration, and height calibration. 
The results of comparing the new GCP coordinates with prior-year reference coordinates are shown in Figure 9. Position errors at the front left and front right corner of the lower layer for the four GCPs were within $5.6 \mathrm{~cm}$ for horizontal and $7.3 \mathrm{~cm}$ for vertical (Figure 9a). The direction error from right to left corner was from 1.2 to 2.6 degrees (Figure 9b). Average errors were $2.3 \mathrm{~cm}, 4.2 \mathrm{~cm}$, and 1.9 degrees for horizontal position, vertical position, and direction, respectively (Table 3 ). These average errors indicate that the low-cost GPS units used with the GCPs in this study enable the GCPs to have potential for future UAV remote-sensing applications. In current agricultural remote-sensing research, GCPs are typically placed in the field, their positions are carefully measured, and they are manually identified in the resulting images for georeferencing of the image mosaics. The image processes are commonly implemented in commercial geographic information systems (GIS) software like ArcGIS or image-analysis software like ENVI. An automated georeferencing algorithm was developed in recent research [23] to automatically identify the GCPs in an image mosaic. Once identified, information on position, reflectance, and crop height could be readily extracted and applied for georeferencing, radiometric calibration, and height calibration, respectively. The computational efficiency of this algorithm could be vastly improved if small search zones could be defined in the initial image mosaic based on known positions of the GCPs. The lower the position error of the GCPs, the more efficient the algorithm.

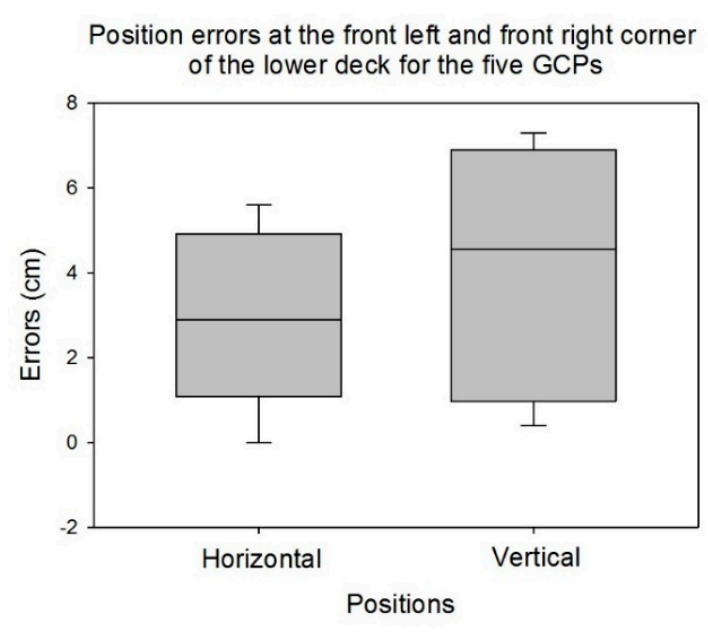

(a)

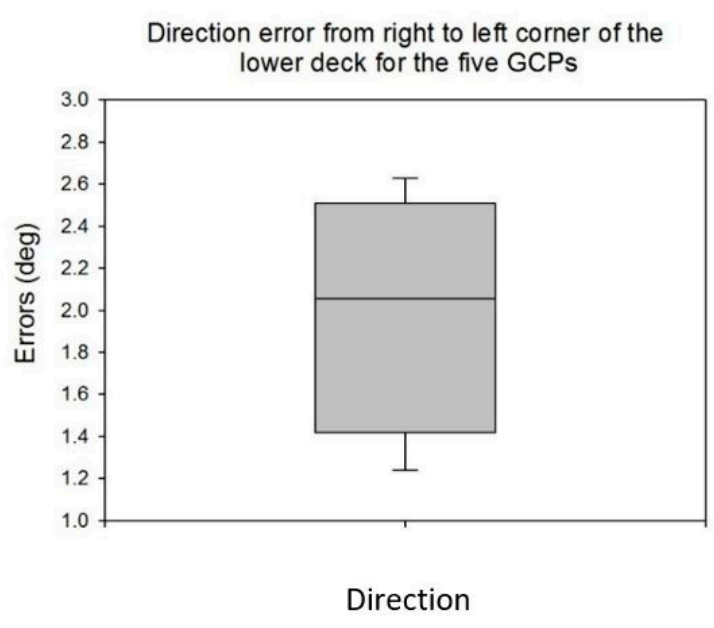

(b)

Figure 9. Errors of (a) the horizontal position, vertical position, and (b) direction measured with the developed GCPs system.

Table 3. Root mean square, standard deviation, and average error results measured for horizontal position, vertical position, and direction of the developed GCPs in the field.

\begin{tabular}{cccc}
\hline & RMSE & STDV & AVG \\
\hline Horizontal position & $3.3 \mathrm{~cm}$ & $2.1 \mathrm{~cm}$ & $2.3 \mathrm{~cm}$ \\
Vertical position & $4.6 \mathrm{~cm}$ & $2.8 \mathrm{~cm}$ & $4.2 \mathrm{deg}$ \\
Direction & $1.9 \mathrm{deg}$ & $0.5 \mathrm{deg}$ & $1.9 \mathrm{deg}$ \\
\hline
\end{tabular}

\subsection{Performance of the Wireless Network}

Figure 10 shows the user interface (UI) of the GCP data collection program, which was deployed on the monitoring terminal for observation and functioned as designed during the experiments. As shown on the UI screen, the GCP data were displayed in relation to their string format to include each GCP's device ID, left and right side coordinates, elevation, and direction. The signals from the RTK-GPS on the fixed-wing UAV were transmitted through the wireless network to the GCP data collection program, allowing the movement of the UAV to be displayed in real time. The wireless 
network was highly reliable, with failure-free operation in the field test at distances between ground station and each GCP, and also between the ground station and UAV, of up to $1.6 \mathrm{~km}$.

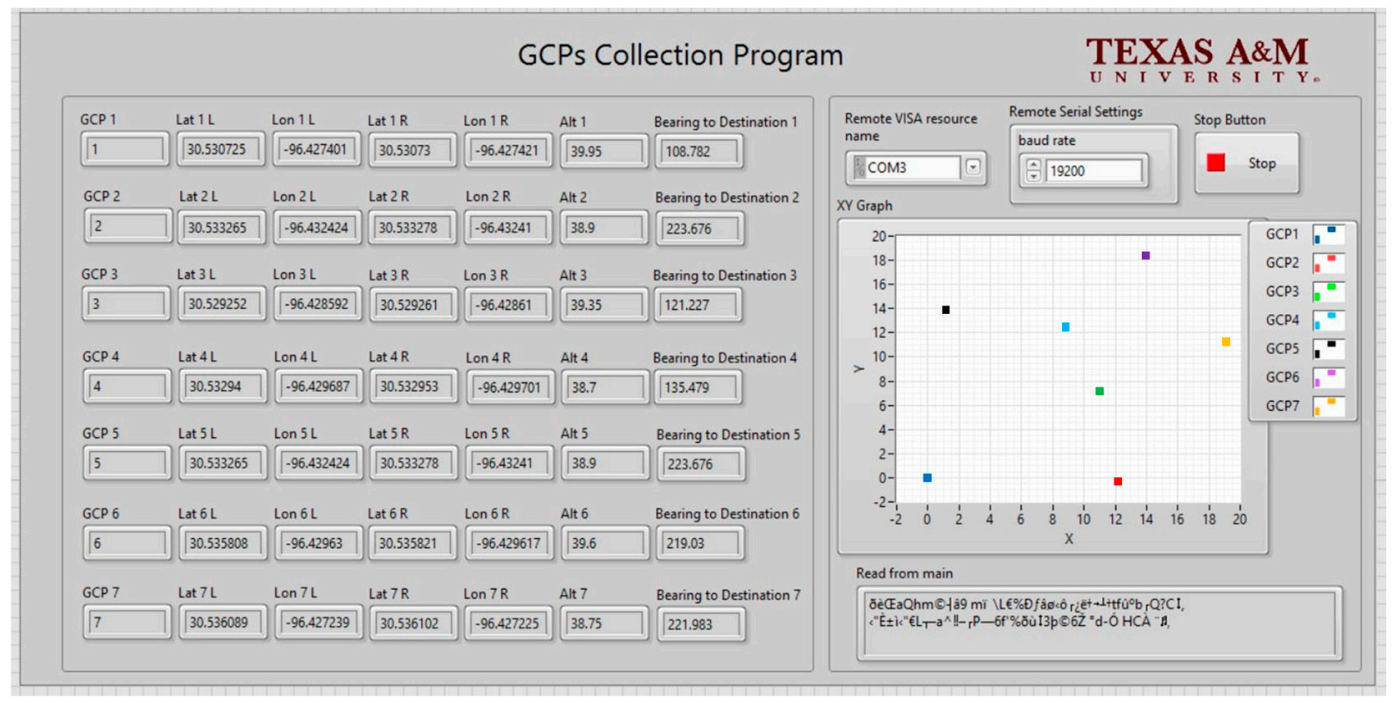

Figure 10. User interface of the GCPs collection program.

The GPS data of the seven GCPs—-device ID, positions on left and right sides of the GCP, elevation, and direction-were automatically recorded in the txt file (Table 4) on the fixed-wing UAV in real time during the flight. The GCP txt files could be used to enable efficient fully automated extraction of GCP information during post-processing of images. As mentioned previously, a prior study [22] involved automating georeferencing and radiometric correction of UAV-based image mosaics. Applications requiring high-quality georeferencing of image mosaics require accurate GCP position data, and the GCPs in this study can provide such data. In future applications, the GCP data file generated in this study could be embedded into image metadata as a header file, so that georeferencing and radiometric calibration of UAV-based mosaics could be automated for higher speed, lower cost, and higher objectivity than current common manual methods.

Table 4. Format of the GPS data of the GCPs recorded in a txt file on the UAV.

\begin{tabular}{ccccccc}
\hline GCP No. & $\begin{array}{c}\text { Latitude_L } \\
\text { (deg) }\end{array}$ & $\begin{array}{c}\text { Longitude_L } \\
\mathbf{( d e g})\end{array}$ & $\begin{array}{c}\text { Latitude_R } \\
\mathbf{( d e g})\end{array}$ & $\begin{array}{c}\text { Longitude_R } \\
\mathbf{( d e g})\end{array}$ & $\begin{array}{c}\text { Elevation } \\
(\mathbf{m})\end{array}$ & $\begin{array}{c}\text { Direction } \\
\text { (deg) }\end{array}$ \\
\hline 1 & 30.530725 & -96.427479 & 30.530734 & -96.427497 & 39.95 & 121.39 \\
2 & 30.529293 & -96.428584 & 30.529280 & -96.428597 & 39.30 & 40.10 \\
3 & 30.532036 & -96.428840 & 30.532049 & -96.428853 & 38.55 & 138.40 \\
4 & 30.533206 & -96.430037 & 30.533219 & -96.430051 & 39.27 & 136.48 \\
5 & 30.533251 & -96.432460 & 30.533264 & -96.432446 & 38.93 & 222.65 \\
6 & 30.535868 & -96.429613 & 30.535881 & -96.429599 & 39.60 & 221.58 \\
7 & 30.536026 & -96.427197 & 30.536014 & -96.427183 & 38.45 & 316.52 \\
\hline
\end{tabular}

\subsection{Field Validation Test}

Table 5 shows the radiometric calibration coefficients derived by fitting the digital number (DN) values of the images to the reflectance data of the calibration targets for each of the red, green, blue, red edge, and near infrared (NIR) bands. The results indicated that DN values could be successfully converted into reflectance data by way of linear relationships with $\mathrm{R}^{2}$ values in the range of $0.9622-0.9943$ for all five bands. The $\mathrm{R}^{2}$ values of the red edge and NIR bands were clearly lower than with the other bands. However, all the radiometric calibrations indicated a strong correlation between ground reflectance and the images' DN values. Thus, radiometric calibration can be used to 
minimize the effects of variation in illumination and atmospheric conditions on UAV images taken at different times [37].

Table 5. Radiometric calibration coefficients of the multispectral camera.

\begin{tabular}{cccc}
\hline Band & K (Slope) & $\mathbf{C}$ (Intercept) & $\mathbf{R}^{\mathbf{2}}$ \\
\hline $475 \mathrm{~nm}$ & 0.001334 & -3.423 & 0.9906 \\
$560 \mathrm{~nm}$ & 0.001192 & -4.849 & 0.9924 \\
$668 \mathrm{~nm}$ & 0.001434 & -4.790 & 0.9943 \\
$717 \mathrm{~nm}$ & 0.001082 & -14.18 & 0.9849 \\
$840 \mathrm{~nm}$ & 0.002539 & -20.72 & 0.9622 \\
\hline
\end{tabular}

In terms of the red, green, and blue bands, the intercept values were similar and close to zero. However, the intercept values of the red edge $(-14.2)$ and NIR $(-20.7)$ bands were much higher than with the visible bands. Not surprisingly, the highest error in reflectance estimation was observed in the NIR band (Figure 11), but the maximum average error was still only $3 \%$. A similar prior study [38] reported a maximum error of $8.0 \%$ and an average error of $2.5 \%$, higher errors than reported here, so the numbers in this study are relatively low. However, based on the results of this study and other related field tests, it was determined that there was excessive noise in the red edge and NIR bands of the multispectral camera used in this work, but even so a maximum 3.0\% reflectance error was found in the field test with the NIR band. The average reflectances of the remaining bands were within $2.0 \%$ of ground values, and usually within $1.0 \%$. The red band had the lowest average errors at $0.78 \%, 0.47 \%$, and $0.50 \%$ for the light gray, medium gray, and dark gray references, respectively. The performance of the radiometric calibration was excellent, providing for a strong relationship $\left(R^{2}=0.99\right)$ between UAV estimates and ground reflectance of the validation GCPs across all camera bands (Figure 12). While the calibration data came from three references of differing gray levels, it is clear that the calibration data consist of four clusters of points. The points at around $75 \%$ reflectance indicate that the NIR band on the light gray reference was significantly higher than reflectance of that reference in the other bands. The slope and offset of the regression line between UAV-based estimates of GCPs reflectance and ground measurements were 0.98 and 0.14 , respectively. Therefore, it is clear that the GCP system evaluated in this study provides the potential for high-quality radiometric calibration of multispectral UAV image mosaics.

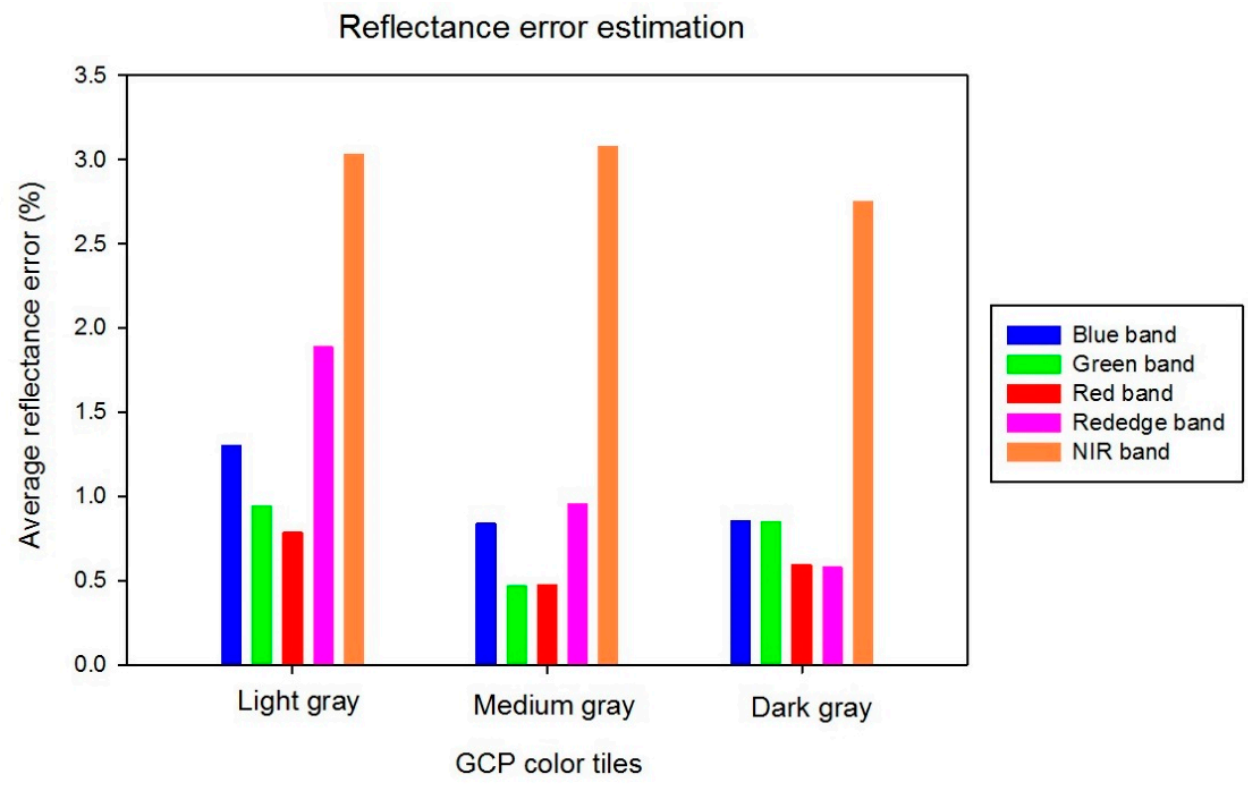

Figure 11. Average reflectance calibration error for each color tile and each band. 
UAV-estimated and ground-truth reflectance of the validation GCPs

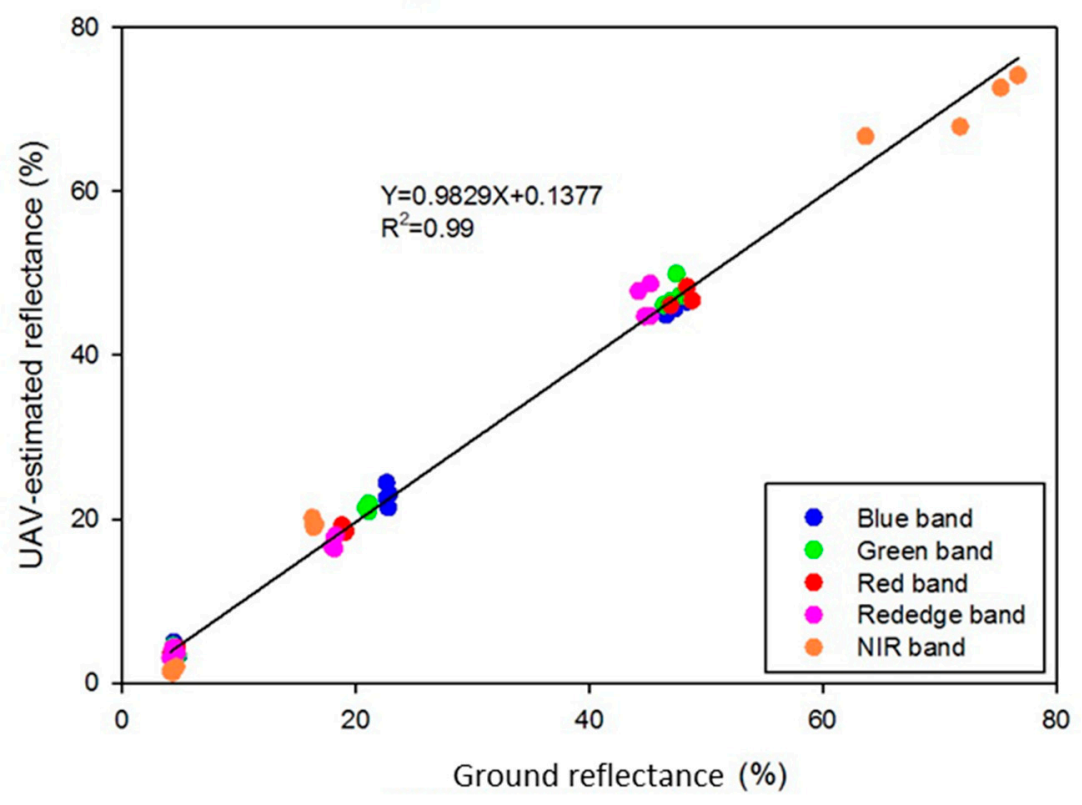

Figure 12. Correlations between UAV-estimated reflectance and ground reflectance for all five bands.

The average difference between UAV height estimates and ground measurements of the validation GCPs is shown in Table 6. Relatively low $(<10 \mathrm{~cm})$ average height error existed for the lower and upper GCP layers. Part of the reason for the height error is the inherent error in vertical position measurements with the RTK-GPS system, which affects the position accuracy of the GCPs used to correct the data on UAV images [3,39,40]. That vertical error determined in this study averaged $4.2 \mathrm{~cm}$. Prior work [15] indicated that image pixels of known-height ground references collected from a fixed-wing UAV at $120 \mathrm{~m}$ AGL can be used to calibrate the DSM reasonably well for the purpose of reducing height errors. Results of the current study tend to corroborate that finding, with object height errors similar to the better results of the prior work. It should thus be possible to effectively apply the new GCPs for height calibration if they are appropriately distributed across the field.

Table 6. Average height errors for lower and upper GCP layers on each color tile.

\begin{tabular}{ccc}
\hline Color Tile & GCP Layer & Height Error \\
\hline \multirow{2}{*}{ Light gray } & Upper & $8.04 \mathrm{~cm}$ \\
& Lower & $9.08 \mathrm{~cm}$ \\
Medium gray & Upper & $8.47 \mathrm{~cm}$ \\
& Lower & $9.67 \mathrm{~cm}$ \\
\multirow{2}{*}{ Dark gray } & Upper & $7.95 \mathrm{~cm}$ \\
& Lower & $9.86 \mathrm{~cm}$ \\
\hline
\end{tabular}

\subsection{Advantages and Limitations}

The main advantages of the system proposed in this study are as follows: (1) That the multifunctional GCP enables image data calibration of not only position, but also reflectance and object height; (2) that the low-cost and high-accuracy GPS receivers onboard the GCP enable autonomous position and attitude measurement; and (3) that the wireless network technology enables GCP position data to be saved alongside image data onboard the UAV. Taken together these capabilities mitigate the following problems: (a) High error in position, reflectance, and plant height; (b) the labor and time required for surveying GCPs for remote sensing of crops in a large field during a growing season; and (c) the requirement for manual identification of GCPs in large image mosaics and manual extraction of their digital numbers for calibration. Even though direct georeferencing could potentially 
replace conventional single-purpose GCPs in some circumstances [9], the multifunctional, autonomous, ground-based system in this research provides multiple additional benefits over simply georeferencing. Some limitations of the proposed system include cost of each GCP, which would likely be a few hundred dollars (USD in 2019) on the open market. Thus, such a system is likely commercially practical only in high-value crops. Another possible concern is having two layers of references on the GCP, which tends to make the GCP large for some high-value applications like vineyards. Furthermore, modifications to current UAVs are required to enable the system to operate as designed. One point of note, however, is that the functions of the main control terminal-which was positioned on the ground in this experimental setup-could potentially be moved to the single-board computer on the UAV to simplify the ground system, and even base stations would not be required if some type of local correction signal would be commonly available.

\section{Conclusions}

A multifunctional GCP system was developed for the purposes of minimizing GCP setup time and improving efficiency in data collection, mosaicking, georeferencing, and calibration of the orthomosaic for plant reflectance and height measurements. A wireless network was developed for automatic collection of GCP position data and communication with UAV. The system enabled recording of all GCP data onboard a fixed-wing UAV in real time during a flight mission. Average errors of position measurements with the GCP receivers were $2.3 \mathrm{~cm}$ horizontal position, $4.2 \mathrm{~cm}$ vertical position, and 1.9 degrees direction, suggesting that such a GCP system with inexpensive GPS receivers could provide reasonable accuracy and precision for UAV remote-sensing missions. Strong correlation $\left(R^{2}=0.99\right)$ was consistently observed between UAV reflectance estimates based on radiometrically calibrated mosaics and actual ground reflectance. Average reflectance errors were less than $3 \%$ for all bands and generally less than 1\% for the RGB bands. Average height error was within $10 \mathrm{~cm}$ for the lower and upper layers of the validation GCPs. The GCP system detailed in this article has excellent potential for multiple referencing purposes to reduce remote-sensing error and for automatic real-time communication to maximize efficiency.

Author Contributions: Conceptualization, X.H. and J.A.T.; Methodology, X.H., J.A.T. and Y.X.; Software, X.H. and Y.X.; Validation, X.H. and H.G.; Formal analysis, X.H.; Investigation, X.H.; Resources, Y.X.; Data curation, X.H. and J.A.T.; Writing—original draft preparation, X.H.; Writing—review and editing, J.A.T., H.G., P.K.Y. and W.L.R.; Supervision, J.A.T. and W.L.R.; Funding acquisition, J.A.T. and W.L.R.

Funding: This work was funded by Texas A\&M AgriLife Research, the United Sorghum Checkoff Program-Expansion of AgriLife Research TERRA Activities to Grain Sorghum (No. CI016-16), and USDA NIFA-Enhancing Accessibility, Reliability, and Validation of Actionable Information from the UAV-Image Data (No. 191000.321646.01).

Acknowledgments: The authors would like to express their sincere gratitude to the anonymous reviewers for their very useful and valuable comments that helped significantly in improving the quality of this paper.

Conflicts of Interest: The authors declare no conflict of interest.

\section{References}

1. Swain, K.C.; Thomson, S.J.; Jayasuriya, H.P. Adoption of an unmanned helicopter for low-altitude remote sensing to estimate yield and total biomass of a rice crop. Trans. ASABE 2010, 53, 21-27. [CrossRef]

2. Gonzalez-Dugo, V.; Zarco-Tejada, P.; Nicolás, E.; Nortes, P.A.; Alarcón, J.J.; Intrigliolo, D.S.; Fereres, E.J. Using high resolution UAV thermal imagery to assess the variability in the water status of five fruit tree species within a commercial orchard. Precis. Agric. 2013, 14, 660-678. [CrossRef]

3. Bendig, J.; Bolten, A.; Bennertz, S.; Broscheit, J.; Eichfuss, S.; Bareth, G. Estimating biomass of barley using crop surface models (CSMs) derived from UAV-based RGB imaging. Remote Sens. 2014, 6, 10395-10412. [CrossRef]

4. Xiang, H.; Tian, L. Method for automatic georeferencing aerial remote sensing (RS) images from an unmanned aerial vehicle (UAV) platform. Biosyst. Eng. 2011, 108, 104-113. [CrossRef] 
5. Gómez-Candón, D.; De Castro, A.I.; López-Granados, F. Assessing the accuracy of mosaics from unmanned aerial vehicle (UAV) imagery for precision agriculture purposes in wheat. Precis. Agric. 2014, 15, 44-56. [CrossRef]

6. Wang, J.; Ge, Y.; Heuvelink, G.B.; Zhou, C.; Brus, D. Effect of the sampling design of ground control points on the geometric correction of remotely sensed imagery. Int. J. Appl. Earth Obs. 2012, 18, 91-100. [CrossRef]

7. Hugenholtz, C.H.; Whitehead, K.; Brown, O.W.; Barchyn, T.E.; Moorman, B.J.; LeClair, A.; Riddell, K.; Hamilton, T. Geomorphological mapping with a small unmanned aircraft system (sUAS): Feature detection and accuracy assessment of a photogrammetrically-derived digital terrain model. Geomorphology 2013, 194, 16-24. [CrossRef]

8. Patias, P.; Giagkas, F.; Georgiadis, C.; Mallinis, G.; Kaimaris, D.; Tsioukas, V. Evaluating horizontal positional accuracy of low-cost UAV orthomosaics over forest terrain using ground control points extracted from different sources. In Proceedings of the International Conference on Remote Sensing and Geoinformation of the Environment, International Society for Optics and Photonics, Paphos, Cyprus, 20-23 March 2017; p. 104440U.

9. Turner, D.; Lucieer, A.; Wallace, L. Direct georeferencing of ultrahigh-resolution UAV imagery. IEEE Trans. Geosci. Remote Sens. 2014, 52, 2738-2745. [CrossRef]

10. Wells, R.R.; Momm, H.G.; Castillo, C. Quantifying uncertainty in high-resolution remotely sensed topographic surveys for ephemeral gully channel monitoring. Earth Surf. Dyn. 2017, 5, 347. [CrossRef]

11. Propeller. Available online: https://www.propelleraero.com/aeropoints/ (accessed on 10 August 2018).

12. Johansen, K.; Raharjo, T. Multi-temporal assessment of lychee tree crop structure using multi-spectral RPAS imagery. Int. Arch. Photogramm. Remote Sens. Spat. Inf. Sci. 2017, 42, 165. [CrossRef]

13. Johansen, K.; Raharjo, T.; McCabe, M. Using multi-spectral UAV imagery to extract tree crop structural properties and assess pruning effects. Remote Sens. 2018, 10, 854. [CrossRef]

14. Chiang, K.W.; Tsai, M.L.; Chu, C.H. The development of an UAV borne direct georeferenced photogrammetric platform for ground control point free applications. Sensors 2012, 12, 9161-9180. [CrossRef] [PubMed]

15. Smhh, D.P.; Atkinson, S.F. Accuracy of rectification using topographic map versus GPS ground control points. Photogramm. Eng. Remote Sens. 2001, 67, 565-570.

16. Cooley, T.; Anderson, G.P.; Felde, G.W.; Hoke, M.L.; Ratkowski, A.J.; Chetwynd, J.H.; Gardner, J.A.; Adler-Golden, S.M.; Matthew, M.W.; Berk, A.; et al. FLAASH, a MODTRAN4-based atmospheric correction algorithm, its application and validation. In Proceedings of the IEEE International Geoscience and Remote Sensing Symposium, Toronto, ON, Canada, 24-28 June 2002; pp. 1414-1418.

17. Iqbal, F.; Lucieer, A.; Barry, K. Simplified radiometric calibration for UAS-mounted multispectral sensor. Eur. J. Remote Sens. 2018, 51, 301-313. [CrossRef]

18. Han, X.; Thomasson, J.A.; Bagnall, G.C.; Pugh, N.A.; Horne, D.W.; Rooney, W.L.; Jung, J.; Chang, A.; Malambo, L.; Popescu, S.C.; Gates, I.T.; Cope, D.A. Measurement and calibration of plant-height from fixed-wing UAV images. Sensors 2018, 18, 4092. [CrossRef] [PubMed]

19. Satirapod, C.; Homniam, P. GPS precise point positioning software for ground control point establishment in remote sensing applications. J. Surv. Eng. 2006, 132, 11-14. [CrossRef]

20. Forlani, G.; Dall'Asta, E.; Diotri, F.; Cella, U.M.D.; Roncella, R.; Santise, M. Quality assessment of DSMs produced from UAV flights georeferenced with on-board RTK positioning. Remote Sens. 2018, 10, 311. [CrossRef]

21. Agüera-Vega, F.; Carvajal-Ramírez, F.; Martínez-Carricondo, P. Assessment of photogrammetric mapping accuracy based on variation ground control points number using unmanned aerial vehicle. Measurement 2017, 98, 221-227.

22. Oniga, V.E.; Breaban, A.I.; Statescu, F. Determining the optimum number of ground control points for obtaining high precision results based on UAS images. Proceedings 2018, 2, 352. [CrossRef]

23. Thomasson, J.A.; Shi, Y.; Sima, C.; Yang, C.; Cope, D.A. Automated geographic registration and radiometric correction for UAV-based mosaics. In Proceedings of the Autonomous Air and Ground Sensing Systems for Agricultural Optimization and Phenotyping, International Society for Optics and Photonics, San Diego, CA, USA, 6-10 August 2017; p. 102180K.

24. Anisi, M.H.; Abdul-Salaam, G.; Abdullah, A.H. A survey of wireless sensor network approaches and their energy consumption for monitoring farm fields in precision agriculture. Precis. Agric. 2015, 16, $216-238$. [CrossRef] 
25. Capraro, F.; Tosetti, S.; Rossomando, F.; Mut, V.; Vita Serman, F. Web-based system for the remote monitoring and management of precision irrigation: a case study in an arid region of Argentina. Sensors 2018, 18, 3847. [CrossRef] [PubMed]

26. Liu, B. Wireless Sensor Network Applications in Precision Agriculture. J. Agric. Syst. Technol. Manag. 2018, 29, 25-37.

27. Gong, S.; Zhang, C.; Ma, L.; Fang, J.; Wang, S. Design and implementation of a low-power ZigBee wireless temperature humidity sensor network. In Proceedings of the International Conference on Computer and Computing Technologies in Agriculture, Nanchang, China, 22-25 October 2010; pp. 616-622.

28. Matijevics, I. Wireless sensors networks-theory and practice. In Towards Intelligent Engineering and Information Technology; Springer: Berlin/Heidelberg, Germany, 2009; pp. 405-417.

29. Hwang, J.; Shin, C.; Yoe, H. Study on an agricultural environment monitoring server system using wireless sensor networks. Sensors 2010, 10, 11189-11211. [CrossRef] [PubMed]

30. Chaudhary, D.D.; Nayse, S.P.; Waghmare, L.M. Application of wireless sensor networks for greenhouse parameter control in precision agriculture. Int. J. Wirel. Mob. Netw. 2011, 3, 140-149. [CrossRef]

31. Zhu, Y.; Song, J.; Dong, F. Applications of wireless sensor network in the agriculture environment monitoring. Procedia Eng. 2011, 16, 608-614. [CrossRef]

32. Gao, R.; Zhou, H.; Su, G. A wireless sensor network environment monitoring system based on TinyOS. In Proceedings of the International Conference on Electronics and Optoelectronics, Dalian, Liaoning, China, 29-31 July 2011; p. V1-497.

33. Li, L.L.; Yang, S.F.; Wang, L.Y.; Gao, X.M. The greenhouse environment monitoring system based on wireless sensor network technology. In Proceedings of the IEEE International Conference on Cyber Technology in Automation, Control, and Intelligent Systems, Kunming, China, 20-23 March 2011; pp. 265-268.

34. Online Positioning User Service. Available online: https://www.ngs.noaa.gov/OPUS/ (accessed on 27 April 2018).

35. Kim, D.W.; Yun, H.; Jeong, S.J.; Kwon, Y.S.; Kim, S.G.; Lee, W.; Kim, H.J. Modeling and testing of growth status for Chinese cabbage and white radish with UAV-based RGB imagery. Remote Sens. 2018, 10, 563. [CrossRef]

36. Ouédraogo, M.M.; Degré, A.; Debouche, C.; Lisein, J. The evaluation of unmanned aerial system-based photogrammetry and terrestrial laser scanning to generate DEMs of agricultural watersheds. Geomorphology 2014, 214, 339-355. [CrossRef]

37. Yun, H.S.; Park, S.H.; Kim, H.J.; Lee, W.D.; Do Lee, K.; Hong, S.Y.; Jung, G.H. Use of unmanned aerial vehicle for multi-temporal monitoring of soybean vegetation fraction. J. Biosyst. Eng. 2016, 41, 126-137. [CrossRef]

38. Del Pozo, S.; Rodríguez-Gonzálvez, P.; Hernández-López, D.; Felipe-García, B. Vicarious radiometric calibration of a multispectral camera on board an unmanned aerial system. Remote Sens. 2014, 6, 1918-1937. [CrossRef]

39. Bendig, J.; Bolten, A.; Bareth, G. UAV-based imaging for multi-temporal, very high resolution crop surface models to monitor crop growth variability. J. Photogramm. Remote Sens. Geoinf. Process. 2013, 6, 551-562.

40. Ruiz, J.; Diaz-Mas, L.; Perez, F.; Viguria, A. Evaluating the accuracy of DEM generation algorithms from UAV imagery. Int. Arch. Photogramm. Remote Sens. Spat. Inf. Sci. 2013, 40, 333-337. [CrossRef]

(C) 2019 by the authors. Licensee MDPI, Basel, Switzerland. This article is an open access article distributed under the terms and conditions of the Creative Commons Attribution (CC BY) license (http://creativecommons.org/licenses/by/4.0/). 